\title{
Epidemiological Characteristics of COVID-19 under Government-mandated Control Measures in Inner Mongolia, China
}

\section{Sha Du}

Inner Mongolia Medical University

Haiwen Lu

Inner Mongolia Medical University

\section{Yuenan Su}

Inner Mongolia Medical University

\section{Shufeng Bi}

Chifeng Center for Disease Control and Prevention

\section{Jing Wu}

Chinese Center for Disease Control and Prevention

\section{Wenrui Wang}

Inner Mongolia Center for Disease Control and Prevention

\section{Xinhui Yu}

Inner Mongolia Medical University

\section{Min Yang}

Inner Mongolia Medical University

Huiqiu Zheng

Inner Mongolia Medical University

Xuemei Wang ( $\nabla$ wangxm_zsu@163.com)

Inner Mongolia Medical University https://orcid.org/0000-0003-0298-9695

\section{Research Article}

Keywords: COVID-19, Characteristics, Control measures, Inner Mongolia

Posted Date: August 12th, 2020

DOI: https://doi.org/10.21203/rs.3.rs-57472/v1

License: (1) (1) This work is licensed under a Creative Commons Attribution 4.0 International License.

Read Full License 


\section{Abstract}

\section{Background}

There were 75 local confirmed cases during the COVID-19 epidemic followed by an outbreak of Wuhan in Inner Mongolia. The aims of our study were to provide reference to control measures of COVID-19 and scientific information for supporting government decision-making for serious infectious disease, in remote regions with relatively insufficient medical resources like Inner Mongolia.

\section{Methods}

The data published by Internet were summarized in order to describe the epidemiological and clinical characteristics of patients with COVID-19. The basic reproductive number (R 0$)$, incubation period, time from illness onset to confirmed and the duration of hospitalization were analyzed. The composition of imported and local secondary cases and the mild/common and severe/critical cases among different ages, genders and major clinical symptoms were compared.

Results

In 2020, from January 23 to February 19 (less than 1 month), 75 local cases of COVID-19 were confirmed in Inner Mongolia. Among them, the median age was 45 years old $(34.0,57.0)$, and $61.1 \%$ were male and 33 were imported (44.0\%). 29 (38.7\%) were detected through close contact tracking, more than $80.0 \%$ were mild/common cases. The fatality rate was $1.3 \%$ and the basic reproductive number (R 0 ) was estimated to be 2.3. The median incubation period was 8.5 days $(6.0 \sim 12.0)$ and the maximum incubation period reached 28 days. There was a statistically difference in the incubation period between imported and local secondary cases $(P<0.001)$. The duration of hospitalization of patients with incubation period $<8.5$ days was higher than that of patients with incubation period $\geq 8.5$ days ( 30.0 vs. 24.0 days).

\section{Conclusion}

In Inner Mongolia, an early and mandatory control strategy by government associated with the rapidly reduced incidence of COVID-19, by which the epidemic growth was controlled completely. And the fatality rate of COVID-19 was relatively low.

\section{Background}

In late December 2019, the 2019 Coronavirus Disease (COVID-19) occurred firstly in Wuhan, Hubei province, China [1]. The number of cases had increased quickly in many countries around the world, which was declared a public health emergency of international concern (PHEIC) [2]. At the time of preparing this manuscript, more than 118,000 cases had been confirmed among more than 100 countries/regions worldwide [3]. Subsequently, the WHO announced that the COVID-19 had grew into a global pandemic[4]. As of July 5, more than 16 million COVID-19 cases were confirmed, of them 650,850 patients had died in over 200 countries/regions[5]. 
The COVID-19 patients were the main source of infection[6], and COVID-19 asymptomatic infections were also contagious[7]. Human-to-human transmission was thought to mainly via respiratory droplet and contact[8]. The SARS-CoV can survive on surfaces more than $96 \mathrm{~h}$ indicated that people may be infected by air or virus-containing body[9]. Isolating SARS-CoV-2 from the feces and urine of infected patients suggested that it could be transmitted via the fecal-oral urinary route[10]. There also needed scientific evidence to confirm whether the virus could be transmitted via mother-to-child[11-12].The basic reproductive number $\left(R_{0}\right)$ of COVID-19 was generally estimated to be 2.0 to 3.5[13-14], but some studies had found that the $R_{0}$ was as high as $6.47[15]$. The population was generally susceptible to the COVID-19 with no difference in gender or age, but the elderly with chronic diseases had a higher risk of infection and death[16-17].

Perceived the high transmission risk of COVID-19, at the early stage, mandatory and strict control strategies had been implemented in different countries for containing the outbreak of the COVID-19. In China, the Chinese government rapidly initiated a public health emergency response to COVID-19, including lockdown in Wuhan[18]. Travel restrictions and the closure of educational institutions were also one of the earliest measures taken by Chinese authorities. Community-led responses, including lockdown and isolating infected people and contact tracing were critical interventions. All major public gatherings such as Spring Festival, were enforcedly prohibited. As for personal protection, wearing mask and washing hand with sanitizer or disinfectant were effective.

Inner Mongolia, a remote and undeveloped region, is located in northern China, where medical resources is relatively insufficient. On January 23,2020 , the first case of COVID-19 was diagnosed, and once a widespread community transmission occurred, it will bring great pressure on disease control. Fortunately, under the early and strict control measures, especially lockdown and quarantine, the local spread of COVID-19 was successfully controlled less than 1 month $\otimes$ from January 23 to February 19, 75 local confirmed cases had been confirmed, of them 33 (44.0\%) were imported. This different epidemic situation of COVID-19 was worth reporting. Thus, we retrospectively conducted a scientific description and further analysis of the epidemiological and clinical characteristics of the all local COVID-19 confirmed cases under government-mandated control measures, for providing reference to prevention and control measures of COVID-19, and scientific information for supporting government decisionmaking for severe infectious disease in remote regions with relatively insufficient medical resources like Inner Mongolia, China.

\section{Materials And Methods}

\subsection{Study design and participants}

This study was a cross-sectional study, we enrolled all local patients (75) with COVID-19 who were reported from January 23 to February 19 in Inner Mongolia. The data of this study were collected and summarized from various Internet and draw the distribution map of COVID-19 diagnosis cases. We described the epidemiological and clinical characteristics of confirmed cases, and compared 
characteristics between imported and local secondary cases, mild/common and severe/critical cases. The basic reproduction number $\left(R_{0}\right)$, incubation period, time from illness onset to confirmed and the duration of hospitalization were analyzed.

\subsection{Definitions}

The diagnosis of COVID-19 was based on the new coronavirus pneumonia diagnosis and treatment program which were published by the National Health Commission of China[19]. According to the definition in the Technical Guide for Epidemiological Investigation of New Coronavirus Pneumonia Cluster Epidemiology (Version 1), cluster epidemic referred to discovery within a small area (such as a family, a construction site, a unit, etc.) within 14 days $\geq 2$ confirmed cases or asymptomatic infections, and there was the possibility of interpersonal transmission due to close contact, or the possibility of infection due to joint exposure[20].

\subsection{Statistical analysis}

Continuous variables such as age, incubation period, time from illness onset to confirmed and the duration of hospitalization were expressed as median (interquartile range). Categorical variables were expressed as rate or proportion. The $t$-test and the Mann-Whitney $U$ test were used to analyze the different characteristics in our population. The statistical analysis was performed with IBM SPSS Statistics Version 19.0 (IBM Corp, Armonk, NY, USA). We defined $a=0.05$ as the test level, and $P \leq 0.05$ represented statistical significance and all reported $P$ values were two-sided.

\section{Results}

\subsection{The changes in COVID-19 cases reported in Inner Mongolia}

The number of daily new confirmed cases were the largest on February 2 and 4, with 7 cases. The last case was confirmed on February 19, and a total of 75 local cases with COVID-19 were diagnosed within 27 days. Finally, 74 cases were discharged, as shown in Figure 1.

75 confirmed cases were distributed in 11 league/cities (except Alxa League) in Inner Mongolia. Among them, Baotou and Ordos haed more cases, with 22 (53.3\%) diagnosed those two cities. Ulanqab (3), Wuhai (2) and Hinggan League (1) have fewer cases (8.0\%) (Figure 2). The imported cases were mainly distributed in Ordos and Bayannur (10). The local secondary cases were mainly distributed in Baotou and Xilingol League (15) (Figure 3).

The median age of patients was 45 years $(34.0,57.0)$. The maximum age was 86 years and the minimum age was 1 year of patients. There were a large number of cases included in the 20-59 age group 54 (76.1\%). And 15 (19.7\%) aged 60 years and over. There were 44 males $(61.1 \%)$ and 28 females (38.9\%) with a male to female ratio of 1.57: 1 . And $75.0 \%$ of male were between 20 and 59 years, female were mainly between 20 and 69 years (93.0\%) (Figure 4). 
33 cases $(44.0 \%)$ were imported cases and $42(56.0 \%)$ were local secondary cases. There were 18 $(25.4 \%)$ patients returned from epidemic regions to their destination by plane. Among all cases, 29 (38.7\%) were detected through close contact tracking. 27 (36.0\%) had been to Wuhan travel or residence; $46(56.0 \%)$ had contacted with patients closely. 10 (13.4\%) were diagnosed with nucleic acid detection more than 1 time. 57 (76.0\%) were family cluster cases infected by living with the infected person or having dinner together (Table 1).

The main clinical symptoms were fever $(42,56.0 \%)$ and cough $(26,34.7 \%) .63$ (84.0\%) were mild/common cases and 6 (8.0\%) were severe/critical cases. 74 (98.7\%) were discharged, only $1(1.3 \%)$ patient died (Table 1).

Table 1 Epidemiological and clinical characteristics of patients with COVID-19

\begin{tabular}{|c|c|c|}
\hline Variables & \multicolumn{2}{|c|}{ Confirmed cases n (\%) } \\
\hline \multirow[t]{2}{*}{ Case type } & Imported cases & $33(44.0)$ \\
\hline & Local secondary cases & $42(56.0)$ \\
\hline \multirow[t]{4}{*}{ Main mode of transportation } & plane & $18(24.0)$ \\
\hline & bus & $14(18.7)$ \\
\hline & train & $4(5.3)$ \\
\hline & unknown transportation/not used & $39(52.0)$ \\
\hline \multirow[t]{3}{*}{ Case detection method } & active consultation & $45(60.0)$ \\
\hline & close contact detection & $29(38.7)$ \\
\hline & customs medical investigation & $1(1.3)$ \\
\hline \multirow[t]{3}{*}{ Cause of infection } & history of traveling or living in Wuhan & $27(36.0)$ \\
\hline & close contact with confirmed cases & $46(61.3)$ \\
\hline & take the same vehicle as the case & $2(2.7)$ \\
\hline \multirow[t]{2}{*}{ Nucleic acid detection frequency } & 1 time & $65(86.6)$ \\
\hline & $\geq 1$ time & $10(13.4)$ \\
\hline \multirow[t]{2}{*}{ Cluster case } & yes & $57(76.0)$ \\
\hline & no & $18(24.0)$ \\
\hline \multirow[t]{3}{*}{ History of cluster } & living together & $25(43.9)$ \\
\hline & have a party & 18(31.6) \\
\hline & other & $14(24.5)$ \\
\hline \multirow[t]{2}{*}{ Main clinical symptoms } & fever & $42(56.0)$ \\
\hline & cough & $26(34.7)$ \\
\hline \multirow[t]{3}{*}{ Clinical type } & mild/common & $63(84.0)$ \\
\hline & severe & $6(8.0)$ \\
\hline & critical & $6(8.0)$ \\
\hline \multirow[t]{2}{*}{ Outcome } & discharge & 74(98.7) \\
\hline & death & $1(1.3)$ \\
\hline
\end{tabular}

3.3 Characteristics of imported and local secondary cases included in this study

There was no statistically significant difference in the composition of case types in different age, gender, frequency of nucleic acid detection, main clinical symptoms, clinical type, and outcome group ( $P>0.05)$. 
The outcome of the disease showed that 1 imported case died (Table 2).

Table 2 Characteristics of imported and local secondary cases

\begin{tabular}{|c|c|c|c|c|}
\hline Variable & & $\begin{array}{c}\text { Imported cases } \\
\mathrm{n}(\%)\end{array}$ & $\begin{array}{l}\text { Local secondary cases } \\
\qquad \mathrm{n}(\%)\end{array}$ & $P$ \\
\hline \multirow[t]{3}{*}{ Age $^{\#}$ (years) } & $\square 30$ & $7(58.3)$ & $5(41.7)$ & 0.071 \\
\hline & $30 \sim$ & $23(51.1)$ & $22(48.9)$ & \\
\hline & $\geq 60$ & $3(20.0)$ & $12(80.0)$ & \\
\hline \multirow[t]{2}{*}{ Gender } & male & $20(50.0)$ & $20(50.0)$ & 0.263 \\
\hline & female & 13(37.1) & $22(62.9)$ & \\
\hline \multirow[t]{2}{*}{ Nucleic acid detection frequency } & 1time & $28(41.3)$ & $37(56.9)$ & 0.945 \\
\hline & $\geq 1$ time & $5(50.0)$ & $5(50.0)$ & \\
\hline \multirow[t]{2}{*}{ Main clinical symptoms } & fever & $26(61.9)$ & 16(38.1) & 0.571 \\
\hline & cough & $16(55.2)$ & $13(44.8)$ & \\
\hline \multirow[t]{3}{*}{ Clinical type } & mild/common & $25(39.7)$ & $38(60.3)$ & 0.115 \\
\hline & sever & $5(83.3)$ & $1(16.7)$ & \\
\hline & critical & $3(50.0)$ & $3(50.0)$ & \\
\hline \multirow[t]{2}{*}{ Outcome } & discharge & $32(43.2)$ & $42(56.8)$ & - \\
\hline & death & $1(100.0)$ & 0 & \\
\hline
\end{tabular}

\# the data of 39 local secondary cases

\subsection{Characteristics of mild/common and severe/critical cases included in this study}

There was no significant difference in the composition of mild/common and severe/critical cases among different age, gender, frequency of nucleic acid detection, main clinical symptoms and outcome groups ( $P>0.05)$. Among the discharged cases, 11 (14.9\%) were severe/critical. and 1 critical case died (Table 3).

Table 3 Characteristics of mild/common and severe/critical cases

\begin{tabular}{|c|c|c|c|c|}
\hline Variables & & Mild/common cases n(\%) & $\begin{array}{c}\text { Severe/critical } \\
\text { cases } \mathrm{n}(\%)\end{array}$ & $P$ \\
\hline \multirow[t]{3}{*}{ Age(years) } & $\square 30$ & 11(91.7) & $1(8.3)$ & 0.138 \\
\hline & $30 \sim$ & $39(86.7)$ & $6(13.3)$ & \\
\hline & $\geq 60$ & $10(66.7)$ & $5(33.3)$ & \\
\hline \multirow[t]{2}{*}{ Gender } & male & $32(80.0)$ & $8(20.0)$ & 0.312 \\
\hline & female & $31(88.6)$ & $4(11.4)$ & \\
\hline \multirow[t]{2}{*}{ Nucleic acid detection frequency } & 1time & $55(84.6)$ & $10(15.4)$ & $0.657^{\#}$ \\
\hline & $\geq 1$ time & $8(80.0)$ & $2(20.0)$ & \\
\hline \multirow[t]{2}{*}{ Main clinical symptoms } & fever & $33(78.6)$ & $9(21.4)$ & 0.940 \\
\hline & cough & $23(79.3)$ & $6(20.7)$ & \\
\hline \multirow[t]{2}{*}{ Outcome } & discharge & $63(85.1)$ & $11(14.9)$ & - \\
\hline & death & 0 & $1(100.0)$ & \\
\hline
\end{tabular}

\footnotetext{
\#Fisher's exact probability method
} 
3.5 The reproduction number $\mathrm{R}_{0}$, incubation period, time from illness onset to confirmed, duration of hospitalization of patients with COVID-19

The basic reproduction number $R_{0}$ of COVID-19 was estimated to be 2.3. The median incubation period was 8.5 days (6.0-12.0) with a maximum of 28 days. The time from illness onset to confirmed was 4.0 days (2.0-9.0). The duration of hospitalization was 27.0 days (21.3-32.0).

Significant difference was observed in the incubation period between imported cases and local secondary cases $(P<0.001)$. The incubation period of imported cases ( 7.0 days) was lower than that of local secondary cases (11.5 days). There was no significant difference in the time from illness onset to confirmed and duration of hospitalization in imported and local secondary cases $(P>0.05)$.

There was no significant difference in the incubation period, and the time from illness onset to confirmed and duration of hospitalization in mild/common and severe/critical cases ( $P>0.05)$ (Table 4).

Table 4 The incubation period, time from illness onset to confirmed, duration of hospitalization of patients with COVID-19

\begin{tabular}{|c|c|c|c|c|}
\hline \multicolumn{2}{|c|}{ Variables } & \multirow{3}{*}{$\begin{array}{c}\text { Incubation period/d } \\
\qquad M\left(Q_{25}, Q_{75}\right) \\
8.5(6.0,12.0) \\
7.0(3.8,9.0)\end{array}$} & \multirow{3}{*}{$\begin{array}{l}\text { Time from illness onset to confirmed/d } \\
\qquad M\left(Q_{25}, Q_{75}\right) \\
4.0(2.0,9.0) \\
3.0(2.0,10.8)\end{array}$} & \multirow{3}{*}{$\begin{array}{c}\text { Duration of hospitalization/d } \\
\qquad M\left(Q_{25}, Q_{75}\right) \\
27.0(21.3,32.0) \\
28.0(22.0,35.0)\end{array}$} \\
\hline \multicolumn{2}{|c|}{ All confirmed cases } & & & \\
\hline \multirow[t]{2}{*}{ Case type } & imported cases & & & \\
\hline & $\begin{array}{l}\text { local secondary } \\
\text { cases }\end{array}$ & $11.5(7.0,13.0)$ & $5.0(3.0,9.0)$ & $25.0(20.5,32.0)$ \\
\hline$P$ & & $<0.001^{* *}$ & 0.355 & 0.093 \\
\hline \multirow{2}{*}{$\begin{array}{l}\text { Clinical } \\
\text { type }\end{array}$} & mild/common & $9.0(6.0,12.5)$ & $4.0(2.0,10.0)$ & $27.0(21.8,32.0)$ \\
\hline & severe/critical & $8.0(5.5,10.5)$ & $3.0(2.0,8.0)$ & $29.5(18.0,37.3)$ \\
\hline$P$ & & 0.633 & 0.421 & 0.630 \\
\hline
\end{tabular}

${ }^{* *} P<0.01$

There was no significant difference in the composition of mild/common and severe/critical cases among the different incubation period groups $(P>0.05)$. The difference between duration of hospitalization of the patients with different incubation periods was statistically significant $(P=0.032)$. The duration of hospitalization of patients with incubation period $<8.5$ days was higher than that of patients with incubation period $\geq 8.5$ days ( 30.0 vs. 24.0 days). 1 patient with an incubation period $\geq 8.5$ days died.

Table 5 Characteristics of COVID-19 patients with different incubation period

\begin{tabular}{crccc}
\hline \multicolumn{1}{c}{ Variables } & \multicolumn{2}{c}{ Incubation period } & \multirow{2}{c}{$P$} \\
\cline { 3 - 4 } & & $<8.5 \mathrm{~d}$ & $\geq 8.5 \mathrm{~d}$ & \\
\hline Clinical type $\mathrm{n}(\%)$ & mild/common & $21(84.0)$ & $24(82.8)$ & 1.000 \\
& severe/critical & $4(16.0)$ & $5(17.2)$ & \\
\hline Outcome $\mathrm{n}(\%)$ & discharge & $25(100.0)$ & $28(96.6)$ & - \\
\hline Duration of hospitalization/d $M\left(Q_{25} \not Q_{75}\right)$ & $30.0(26.5,35.5)$ & $24.0(20.3,29.8)$ & $0.032^{*}$ \\
\hline
\end{tabular}




\section{Discussion}

The early and mandatory control measures associated with the rapidly reduced incidence of COVID-19 in Inner Mongolia. There were 75 local confirmed cases and not spread widely and not occurred community transmission. All patients were susceptible to COVID-19 with no difference in gender or age. The fatality rate was relatively lower (1.3\%).

A total of 33 imported cases (44.0\%) had been reported in Inner Mongolia, where the basic reproduction number $\left(\mathrm{R}_{0}\right)$ was calculated 2.3 of COVID-19. Although it was lower than Korea (3.58)[21] and German (6.07)[22], the COVID-19 transmissibility was higher. But under the early and mandatory control measures especially lockdown, quarantine and increasing social distance, the growth of local cases was completely controlled within 1 month. In the face of severe respiratory diseases such as COVID-19, if enforced isolation strategies can be taken to block the transmission route in early time, the $\mathrm{R}_{0}$ will decline rapidly in coming days[23] and further ensure that the medical resources can relatively meet the needs of patients. However, because of the limitation of data in our study, the second-generation and the third-generation cases in the local secondary cases could not be accurately distinguished and only obtained a rough estimate of $R_{0}$.

In our study, among 33 imported cases, 18 (54.5\%) cases were returned from epidemic regions to their destination by plane, and they were undetected during the airport surveillance in Inner Mongolia. Of all the confirmed cases, $44.0 \%$ cases had no fever. Asymptomatic infection also a critical source of COVID19[24]. A study on COVID-19 asymptomatic infection showed that an asymptomatic infection may cause infection in 5 people from exposure to confirmed[25]. At that time, the whole country, including Inner Mongolia, a large number of people were returned to work or school. Hohhot, a designated entry point for overseas returnees diverted from Beijing, was facing a high transmission risk of COVID-19. Therefore, we suggest that for high-risk groups (including their close contacts), the scope of laboratory screening should be expanded as much as possible to discover and isolated infected persons in time.

The incubation period of COVID-19 was 8.5 days (6.0 12.0), the maximum incubation period reached 28 days. The average incubation period was within the range of 0-14 days estimated by WHO and 2-12 days predicted by the European Center for Disease Control and Prevention[26]. Some studies had shown that the COVID-19 incubation period was 3.0-7.0 days, generally less than 14 days[13, 27-28]. But previous study had also shown that the maximum incubation period reached 28 days[29]. Haiyan Yang et al. speculated that the incubation period for cases outside Hubei province was 1-20 days[30]. Thus, properly extend the isolation time of suspected cases and their close contacts was a critical measure.

More than 30\% of COVID-19 cases were found through close contact detection in Inner Mongolia. Due to timely detection and treatment, more than $80.0 \%$ of cases were mild/common, with a cure rate of $98.7 \%$. 
The case fatality rate was 1.3\%, lower than Italy (12.63\%)[31], United States (6.1\%)[32] Canada (5.5\%)[32], which indicated that in the case of relatively few COVID-19 patients, the medical resources were relatively adequate. So, patients had been treated timely and effectively like Inner Mongolia.

\section{Conclusion}

In Inner Mongolia, an early and mandatory control strategy by government associated with the rapidly reduced incidence of COVID-19, by which the epidemic growth was controlled completely. And the fatality rate of COVID-19 was relatively low. Until an effective antiviral drug or vaccine is available, the government must need to launch early and strict containment strategy to control the pandemic in countries with relatively insufficient health care systems capacity like Inner Mongolia.

\section{Declarations}

Acknowledgements: We acknowledge all the patients involved in this study, and appreciate all the frontline medical and nursing staff involved in the diagnosis and treatment of patients in Inner Mongolia.

Funding: This study was supported by Inner Mongolia Science and Technology Planning Project (Study on Epidemiological Characteristics and Key Techniques for Prevention and Control of Brucellosis and Q fever).

Authors' contributions: XW contributed to conceiving the study concept and design. SD and $\mathrm{HL}$ analyzed the data and wrote the first draft of the paper. All authors (SD, HL, YS, SB, JW, WW, XY, MY, HZ and XW) contributed to the interpretation of data and were involved revising the manuscript critically for important intellectual content. All authors gave a final approval of the version to be published and agree to be accountable for all aspects of the work.

Competing interests: The authors declared that they have no competing interests

Ethical approval: Not required.

Consent for publication $\square$ Not applicable.

Availability of data and materials $\square$ The datasets used and/or analyzed during the current study are available from the corresponding author on reasonable request.

\section{References}

[1]Zhu N, Zhang D, Wang W, et al. A novel coronavirus from patients with pneumonia in China,2019[J]. N Engl J Med, 2020, 382(8):727-733.doi: 10.1056/NEJMoa2001017.

[2]World Health Organization. Statement on the second meeting of the International Health Regulation (2005) Emergency Committee regarding the outbreak of novel coronavirus (2019-nCoV). 
https://www.who.int/news-room/detail/30-01-2020-stateme -nt-on-the-second-meeting-of-theinternational-health-regulations-(2005)-emerge-ncy -committee-regarding-the-outbreak-of-novelcoronavirus-(2019-ncov).

[3]World Health Organization. WHO Director-General's opening remarks at the media briefing on COVID19-11 March 2020.https://www.who.int/dg/speeches/detail/who-director-general-s-opening-remarks-atthe-media-briefing-on-covid-19-11-march-2020.

[4]World Health Organization. WHO Director-General's opening remarks at the media briefing on COVID19-11 March 2020. https://ww w.who.int/dg/speeches/detail/who-director-general-s-opening-remarks-atthe-media-briefing-on-covid-19-11-march-2020.

[5] World Health Organization. Coronavirus disease (COVID-2019) situation reports. World Health Organization.https://www.who.int/docs/default-source/coronaviruse/situation-reports/2020 0728-covid19-sitrep-190.pdf?sfvrsn=fec17314_2.

[6]Bassetti M, Vena A, Giacobbe DR. The novel Chinese coronavirus (2019-nCoV) infections: Challenges for fighting the storm[J]. Eur J Clin Invest, 2020,50 (3):e13209.doi:10.1111/eci.13209.

[7]Rothe C, Schunk M, Sothmann P, et al. Transmission of 2019-nCoV Infection from an Asymptomatic Contact in Germany[J]. N Engl J Med, 2020, 382(10):970-971.doi:10.1056 / NEJMc2001468.

[8]Wang LS, Wang YR, Ye DW, et al. A review of the 2019 Novel Coronavirus (COVID-1 9) based on current evidence[J].Int J Antimicrob Agents, 2020.doi:1 0.1016/j.ijantimicag.2020.105948.

[9]Harapan H, Itoh N, Yufika A, et al. Coronavirus disease 2019 (COVID-19): A literature review. J Infect Public Health. 2020;13(5):667-673. doi:10.1016/j.jiph.2020.03.019

[10]Xinhuanet Nan-shan ZHONG's and Lan-juan Ll's teams isolated the virus from the stools of patients with new coronary pneumonia. Xinhuanet. http://m.xinhuanet. com/hb/2020-02/13/c_1125570909.htm [Accessed on Feb. 28, 2020]; 2020. (in Chinese)

[11]Riou J, Althaus CL. Pattern of early human-to-human transmission of Wuhan 2019 novel coronavirus (2019-nCoV), December 2019 to January 2020[J]. Euro Surveill, 2020, 25(4). doi:10.2807/1560-7917.

[12]Shi Y, Wang G, Cai XP, et al. An overview of COVID-19. J Zhejiang Univ Sci B. 2020;21(5):343-360. doi:10.1631/jzus.B2000083

[13]Li Q, Guan X, Wu P, et al. Early Transmission Dynamics in Wuhan, China, of Novel CoronavirusInfected Pneumonia[J]. N Engl J Med, 2020, 382(13):1199-1207. doi:10. 1056/ NEJMoa2001316.

[14]Liu Y, Gayle AA, Wilder-Smith A, et al. The reproductive number of COVID-19 is higher compared to SARS coronavirus[J]. J Travel Med, 2020, 27(2).doi:1 0.1093/jtm/taaa021. 
[15]Tang B, Wang X, Li Q, et al. Estimation of the Transmission Risk of the 2019-nCoV and Its Implication for Public Health Interventions[J]. J Clin Med, 2020,9(2). doi:10.3390/jcm9020462.

[16]World Health Organization. Novel Coronavirus (2019-nCoV) advice for the public: Myth buster.http://www.who.int/emergencies/diseases/novel-coronavirus-2019/advice-for-public/myth buster.

[17]Gralinski LE, Menachery VD. Return of the Coronavirus: 2019-nCoV[J]. Viruses, 2020,12(2):135. doi:10.3390/v12020135.

[18] Wang FS, Zhang C. What to do next to control the 2019-nCoV epidemic?. Lancet. 2020;395(10222):391-393. doi:10.1016/S0140-6736(20)30300-7

[19]General Office of National Health Commission of the People's of Republic of China, General Office of National Administration of Traditional Chinese Medicine. General Office of National Health Commission of the People's of Republic of China. Diagnosis and treatment protocol for COVID-19(trial version 7) [EB/OL].(2020-03-03)[2020-03-11]..

[20]Ye Lixia, Wang Haibin, Lu Huaichu, Chen Bingbing, Zhu Yingying, Gu Shaohua, Wang Jianmei, Pan Xingqiang, Fang Ting, Dong Hongjun. Investigation of a cluster epidemic of COVID-19 in Ningbo[J]. Chinese Journal of Epidemiology, 2020, 41(0): 0-0.

[21]Chen TM, Rui J, Wang QP, Zhao ZY, Cui JA, Yin L. A mathematical model for simulating the phasebased transmissibility of a novel coronavirus. Infect Dis Poverty. 2020;9(1):24. Published 2020 Feb 28. doi:10.1186/s40249-020-00640-3

[22]Yuan J, Li M, Lv G, Lu ZK. Monitoring transmissibility and mortality of COVID-19 in Europe. Int J Infect Dis. 2020;95:311-315. doi:10.1016/j.jij.2020.03.050.

[23]Mahase E. China coronavirus: what do we know so far? BMJ (Clinical researched) 2020,368: m308.doi: 10.1136/bmj.m308.

[24]Wang Y, Wang Y, Chen Y, Qin Q. Unique epidemiological and clinical features of the emerging 2019 novel coronavirus pneumonia (COVID-19) implicate special control measures. J Med Virol. 2020;92(6):568-576. doi:10.1002/jmv.25748.

[25]Bulut C, Kato Y. Epidemiology of COVID-19[J]. Turk J Med Sci. 2020;50(SI-1):563-570. doi:10.3906/sag-2004-172.

[26Bai Y, Yao LS, Wei T, et al. Presumed asymptomatic carrier transmission of COVID-19[J]. JAMA, 2020.doi:10.1001/jama.2020.2565.

[27]European Centre for Disease Prevention and Control (ECDC).Q \& A on novel coronavirus. Stockholm:ECDC;2020.https://www.ecdc.europa.eu/en/novel-coronavirus-china/questions-answers. 
[28]Backer JA, Klinkenberg D, Wallinga J. Incubation period of 2019 novel coronavirus (2019-nCoV) infections among travellers from Wuhan, China, 20-28 January 2020. Euro Surveill, 2020,25(5). doi:10.2807/1560-7917.

[29]Guan WJ, Ni ZY, Hu Y, et al. Clinical Characteristics of Coronavirus Disease 2019 in China[J]. N Engl J Med, 2020.doi:10.1056/NEJMoa2002032.

[30] Yang HY, Xu J, Li Y, et al. The preliminary analysis on the characteristics of the cluster for the Corona Virus Disease[J]. Chin J Epidemiol, 2020, 41(5): 623-628. doi: 10.3760/cma.j.cn112338-20200223-00153.

[31] Izzetti R, Nisi M, Gabriele M, et al. COVID-19 Transmission in Dental Practice: Brief Review of Preventive Measures in Italy. J Dent Res. 2020;99(9):1030-1038. doi:10.1177/0022034520920580.

[32] Abdollahi E, Champredon D, Langley JM, Galvani AP, Moghadas SM. Temporal estimates of casefatality rate for COVID-19 outbreaks in Canada and the United States. CMAJ. 2020;192(25):E666-E670. doi:10.1503/cmaj.200711.

\section{Figures}

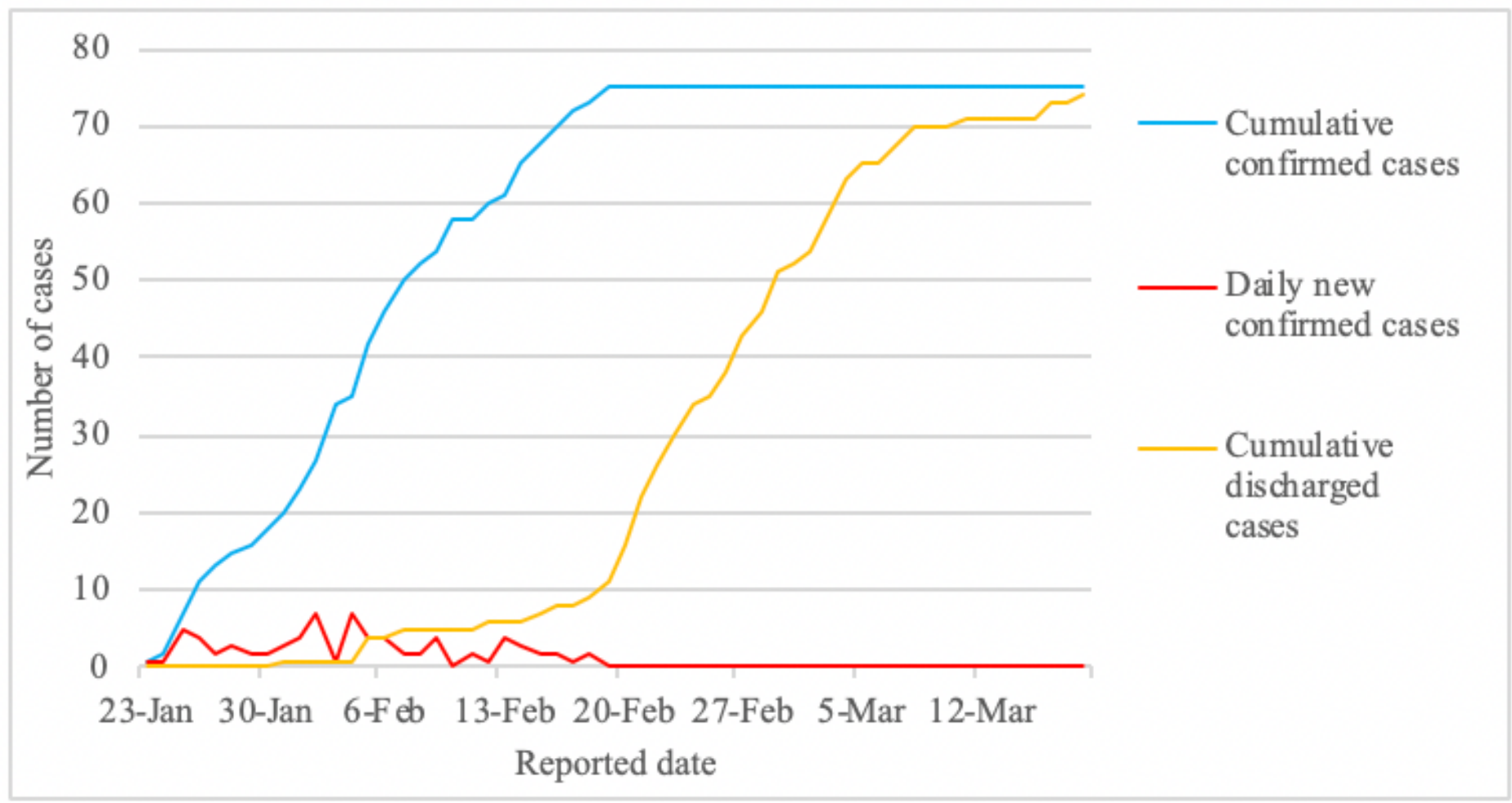

\section{Figure 1}

The changes in COVID-19 cases reported in Inner Mongolia 


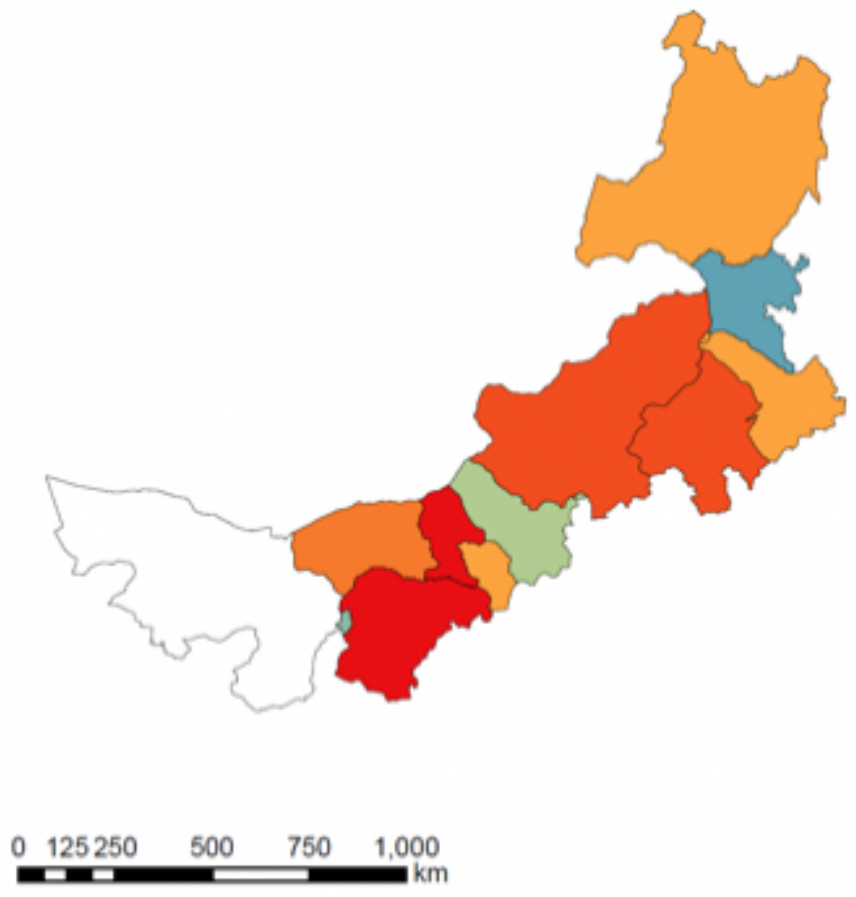

Number of cases

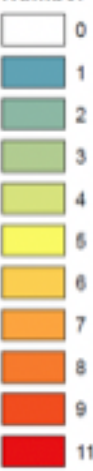

\section{Figure 2}

The distribution of 75 confirmed cases in Inner Mongolia. Note: The designations employed and the presentation of the material on this map do not imply the expression of any opinion whatsoever on the part of Research Square concerning the legal status of any country, territory, city or area or of its authorities, or concerning the delimitation of its frontiers or boundaries. This map has been provided by the authors. 


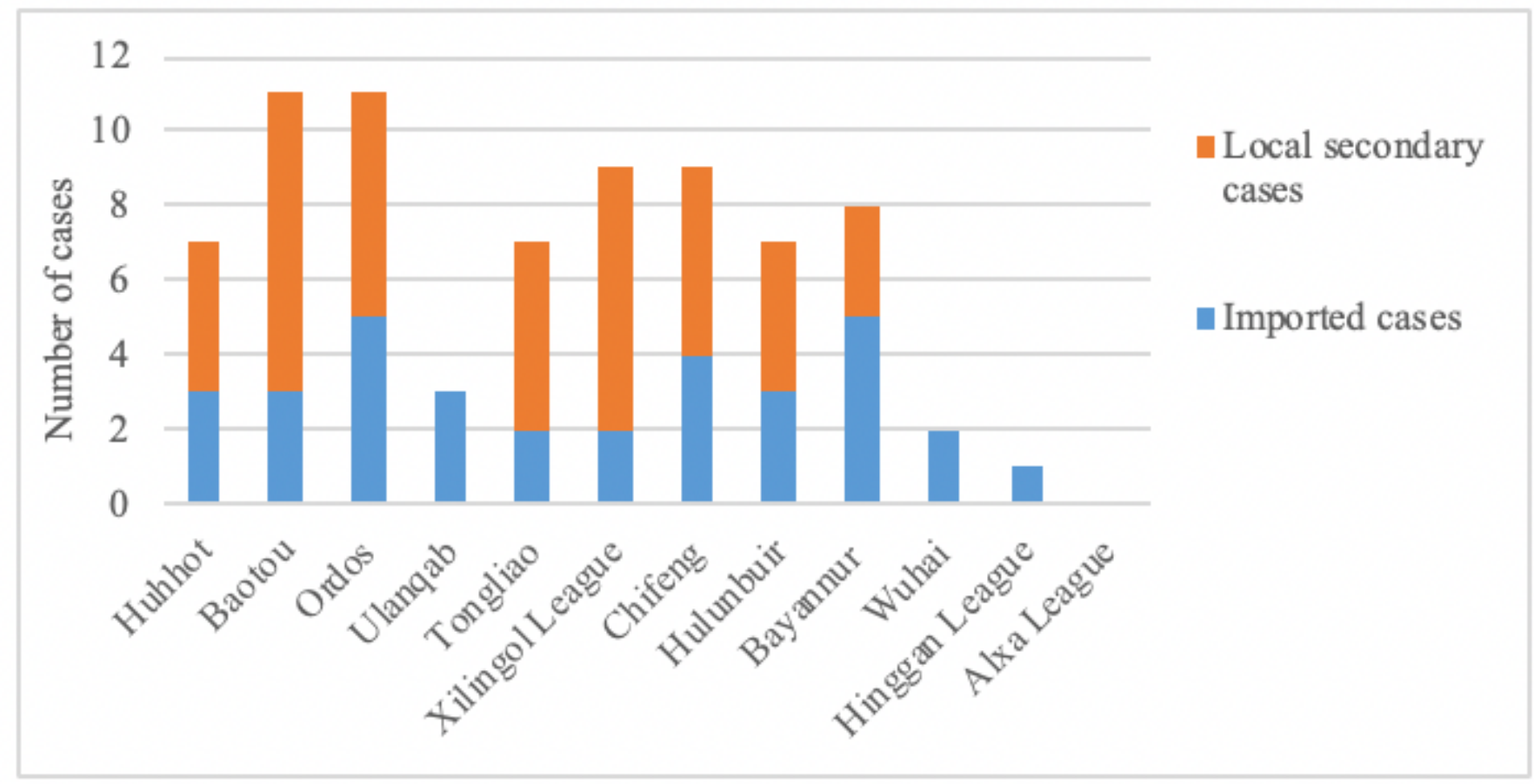

Figure 3

The distribution of imported and local secondary cases in Inner Mongolia

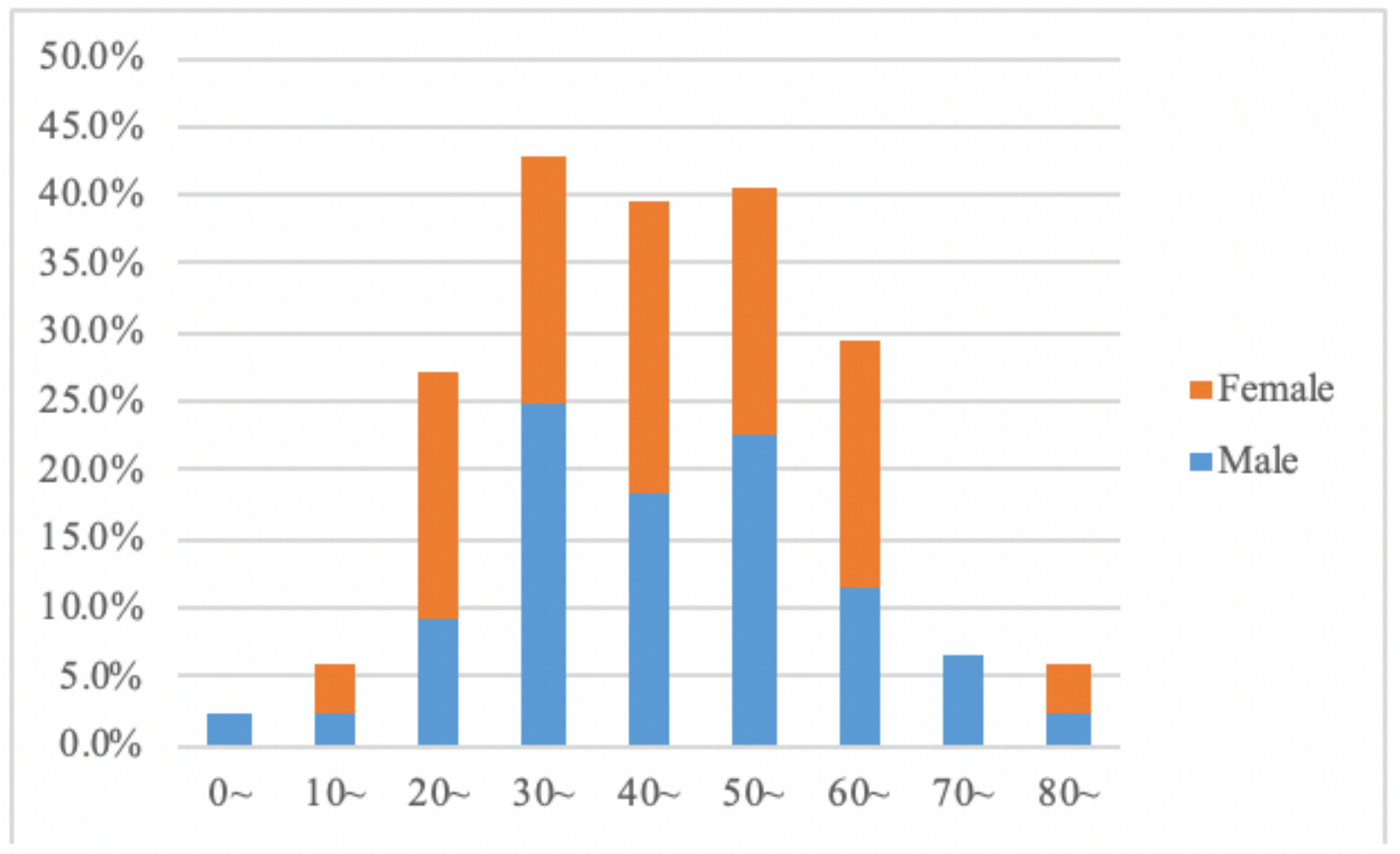


Figure 4

The age and gender distribution of confirmed cases in Inner Mongolia 